\title{
PENGARUH KEPEMIMPINAN, PEMBERDAYAAN DAN MOTIVASI TERHADAP KINERJA PEGAWAI NEGERI SIPIL DI LINGKUNGAN DIREKTORAT PENELITIAN DAN PENGEMBANGAN PADA KEMENTERIAN PEKERJAAN UMUM TIMOR LESTE
}

\author{
Ladislau Maria das Dores de Jesus
}

Fakultas Ekonomi dan Bisnis Universitas Udayana (Unud), Bali, Indonesia

Email : ladislaudejesus@yahoo.com

\begin{abstract}
ABSTRAK
Kepemimpinan memegang peranan penting dalam suatu organisasi. Pemimpin adalah motor pengerak utama dalam organisasi agar semua tujuan, visi dan misi organisasi bisa tercapai. Populasi dalam penelitian ini adalah semua pegawai negeri di kantor Direktorat Penelitian dan Pengembangan Kementerian Pekerjaan Umum Timor Leste. Metode penentuan sampel yang digunakan adalah metode sensus dan jumlah sampel sebanyak 36 orang. Pengujian hipotesis penelitian menggunakan analisis regresi linier berganda dengan program pengola data yaitu SPSS versi 13.0. Hasil penelitian ini menunjukan bahwa : (1) Kepemimpinan berpengaruh positif dan signifikan terhadap kinerja pegawai (2) Pemberdayaan berpengaruh positif dan signifikan terhadap Kinerja Pegawai (3) Motivasi berpengaruh positif dan signifikan terhadap Kinerja Pegawai. Dalam penelitian ini banyak keterbatasan dan apabila akan dilakukan replikasi dimasa datang diharapkan menambah jumlah populasi, obyeknya tidak satu institusi (lebih majemuk), dan sampelnya para karyawan tanpa melihat Jenjang atau strata, dan dimungkinkan ditambah variabel lain yang ada kaitannya dengan tema tersebut.
\end{abstract}

Kata Kunci : Kepemimpinan, Pemberdayaan, Motivasi dan Kinerja

\begin{abstract}
Leadership plays an important role in an organization. Leaders are the main motor drives in the organization so that all goals, vision and mission of the organization can be achieved. The population in this study were all civil servants at the Directorate of Research and Development office of the Ministry of Public Works of Timor Leste. The sampling method used is the census method and the number of samples is 36 people. Testing hypothesis research using multiple linear regression analysis with program pengola data that is SPSS version 13.0. The results of this study show that: (1) Leadership has positive and significant effect on employee performance (2) Empowerment have positive and significant effect to Employee Performance (3) Motivation have positive and significant influence to Employee Performance. In this study many limitations and if it will be replicated in the future is expected to increase the number of population, the object is not one institution (more compound), and the samples of employees without seeing the level or strata, and possible plus other variables that have something to do with the theme.
\end{abstract}

Keywords: Leadership, Empowerment, Motivation and Performance 


\section{PENDAHULUAN}

Setiap organisasi atau perusahaan memerlukan sumber daya untuk mencapai tujuannya. Sumber daya tersebut antara lain terdiri atas sumber daya alam, sumber daya financial, sumber daya manusia, sumber daya ilmu pengetahuan dan sumber daya teknologi. Sumber daya yang terpenting adalah sumber daya manusia (SDM). SDM merupakan sumber daya yang digunakan untuk menggerakan sumber daya lainnya untuk mencapai tujuan organisasi.

Direktorat Penelitian dan Pengembangan Kementerian Pekerjaan Umum Timor Leste adalah salah satu instansi pemerintah yang bertugas untuk menguji material konstruksi dan pengendalian mutu. Untuk itu diharapkan karyawan Direktorat Penelitian dan Pengembangan menunjukan kinerja yang baik.

Menurut Meyer (2008), kepemimpinan adalah mencapai hasil yang spesifik dan bermanfaat melalui orang-orang.

Pemberdayaan dalam suatu organisasi sangat diperlukan dalam menghadapi tantangan persaingan global. Karena setiap induvidu dituntut pro aktif memberikan kontribusinya bagi perkembangan organisasi. Menurut Sarafudin Alwi (2011) mengatakan bahwa pemberdayaan merupakan seni dalam proses mendorong pegawai untuk bekerja secara optimal.

(Wibowo dalam Stephen P. Robbins, 2007) mengatakan bahwa motivasi sebagai proses yang menyebabkan intensitas (intensity), arah (direction), dan usaha terus menerus (persistence) induvidu menuju pencapaian tujuan. Kinerja merupakan hasil yang dapat dicapai oleh seseorang atau sekelompok 
orang dalam suatu organisasi baik secara kuantitatif maupun kualitatif , sesuai dengan wewenang dan tugas tanggung jawab masing-masing dalam upaya mencapai tujuan organisasi bersangkutan secara legal, tidak melanggar hukum dan sesuai dengan moral maupun etika (Moeheriono, 2009).

Motivasi dan Kepemimpinan merupakan beberapa variabel yang mempengaruhi Kinerja Pegawai, hal ini ditunjukan dengan beberapa penelitian yang telah dilakukan antara lain Masrukhin dan Waridin pada Kantor Pengelolaan Pasar Daerah (KPPD) Kabupaten Demak yang mengatakan bahwa variabel motivasi kerja dan kepemimpinan berpengaruh positif dan signifikan terhadap kinerja pegawai. Selanjutnya penelitian yang dilakukan oleh I Putu Magna Anuraga tentang Kepemimpinan dan Pemberdayaan terhadap motivasi dan Kinerja Pegawai Dinas Pendidikan Pemuda dan Olah Raga Kabupaten Tabanan menunjukan bahwa variabel Kepemimpinan dan Pemberdayaan berpengaruh positif dan signifikan terhadap kinerja karyawan.

Berdasarkan uraian diatas maka dilakukan penelitian tentang "Pengaruh kepemimpinan, pemberdayaan dan motivasi terhadap kinerja pegawai negeri sipil dilingkungan Direktorat Penelitian dan Pengembangan Kementerian Pekerjaan Umum Timor Leste”. 


\section{TELAAH TEORI}

\section{KINERJA}

Wibowo dalam Armstrong dan Baron (1998) mengatakan bahwa kinerja adalah hasil kerja yang mempunyai hubungan kuat dengan tujuan strategis organisasi, kepuasan konsumen dan memberikan kontribusi pada peningkatan ekononomi.

\section{KEPEMIMPINAN}

Menurut Meyer (2008) kepemimpinan adalah mencapai hasil yang spesifik dan bermanfaat melalui orang-orang.

\section{PEMBERDAYAAN}

Greenberg dan Baron (dalam Wibowo (2007) menyatakan bahwa pemberdayaan sebagai suatu proses dimana pekerja diberi peningkatan sejumlah otonomi dan keleluasaan dalam hubungannya dengan pekerjaan mereka.

\section{MOTIVASI}

Menurut Siagaan (2004) motivasi adalah daya pendorong yang menyebabkan sesorang anggota organisasi mau dan rela untuk mengerahkan kemampuan dalam bentuk keahlian atau ketrampilan tenaga dan waktunya untuk menyelenggarakan berbagai kegiatan yang menjadi tanggung jawabnya dan menunaikan kewajibannya dalam rangka pencapaian tujuan dan berbagai sasaran organisasi yang ditentukan sebelumnya.

\section{PENELITIAN TERDAHULU}


Penelitian yang dilakukan oleh Idayanti Nursyamsi (2012) tentang “ Pengaruh Kepemimpinan, Pemberdayaan, dan Stress Kerja Terhadap Komitmen Organisasional serta dampaknya terhadap Kinerja Dosen " hasil penelitian menunjukan bahwa terdapat pengaruh positif dan signifikan Kepemimpinan, Pemberdayaan dan Stress Kerja terhadap Kinerja Dosen. Penelitian dilakukan oleh Wilhelmus Andiyanto dan Ismi Darmastuti (2011) tentang “ Pengaruh Motivasi Kerja dan Kepemimpinan terhadap Kinerja Pegawai Pada Badan Keluarga Berencana dan Pemberdayaan Perempuan Kabupaten Manggarai - Flores Nusa Tenggara Timur " hasil penelitian menunjukan bahwa Motivasi Kerja dan Kepemimpinan secara induvidu atau bersama-sama berpengaruh terhadap Kinerja Pegawai.

\section{HIPOTESIS}

H1: $\quad$ Terdapat pengaruh positif dan sinifikan kepemimpinan terhadap kinerja pegawai pada kantor Direktorat Penelitian dan Pengembangan Kementerian Pekerjaan Umum Timor Leste

H2: $\quad$ Terdapat pengaruh positif dan sinifikan pemberdayaan terhadap kinerja pegawai pada kantor Direktorat Penelitian dan Pengembangan Kementerian Pekerjaan Umum Timor Leste.

H3: $\quad$ Terdapat pengaruh positif dan sinifikan motivasi terhadap kinerja pegawai pada kantor Direktorat Penelitian dan Pengembangan Kementerian Pekerjaan Umum Timor Leste. 


\section{KERANGKA KONSEP DAN HIPOTESIS PENELITIAN}

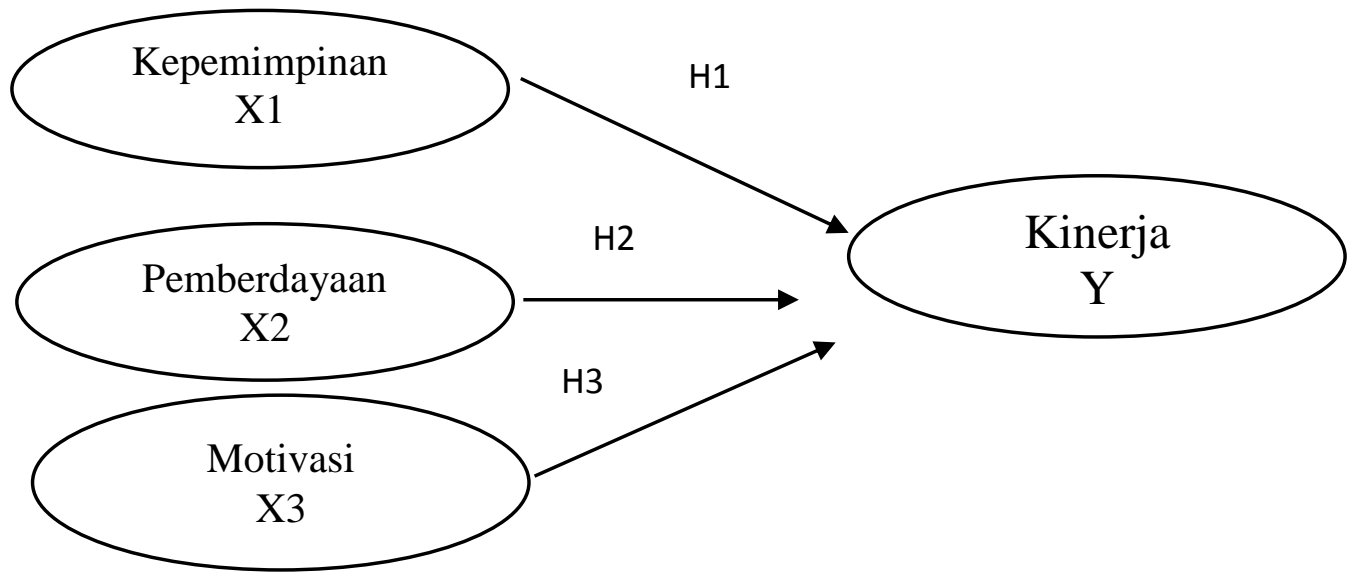

\section{METODE PENELITIAN}

Penelitian dilakukan di Direktorat Penelitian adan Pengembangan

Kementerian Pekerjaan Umum Timor Leste sebanyak 36 responden. Penelitian ini termasuk dalam penelitian sensus. Pengumpulan informasi dilakukan dengan menyebarkan kuesioner dimana didalam tertuang pernyataan - pernyataan dengan jawaban rating scale 1-4.

Variabel penelitian terdiri dari Kepemimpinan (X1), Pemberdayaan (X2), Motivasi (X3) dan Kinerja (Y). Metode penelitian melalui program linera regresi berganda dengan mempergunakan program SPSS 13.00 for windows, dengan formula sebagai berikut :

$\mathrm{Y}=\mathrm{a}+\mathrm{b} 1 . \mathrm{X} 1+\mathrm{b} 2 . \mathrm{X} 2+\mathrm{b} 3 . \mathrm{X} 3$ 


\section{HASIL PENELITIAN}

Berdasarkan data persamaan regresi tersebut di atas dapat dinyatakan dalam persamaan :

$\mathrm{Y}=0.058 \mathrm{X} 0.287 \mathrm{X} 1+0.441 \mathrm{X} 2+0.298 \mathrm{X} 3$

1. b1 (nilai koefisien regresi untuk kepemimpinan) mempunyai nilai parameter positif yaitu sebesar 0,287 mempunyai arti bahwa meningkatnya kepemimpinan yang dilakukan maka kinerja pegawai akan mengalami peningkatan dengan asumsi bahwa variabel lain adalah tetap (konstan).

2. b2 (nilai koefisien regresi pemberdayaan) sebesar 0,441 mempunyai arti bahwa meningkatnya pemberdayaan yang dilakukan, maka hal itu dapat meningkatkan kinerja pegawai dengan asumsi bahwa variabel lain adalah tetap (konstan).

3. b3 (nilai koefisien regresi motivasi) sebesar 0,298 mempunyai arti bahwa meningkatnya motivasi yang dilakukan, maka hal itu dapat meningkatkan kinerja pegawai dengan asumsi bahwa variabel lain adalah tetap (konstan).

4. Berdasarkan nilai koefisien regresi tersebut di atas, maka faktor yang paling besar pengaruhnya (dominan) terhadap kinerja pegawai adalah pemberdayaan , terbukti dengan nilai koefisien regresi sebesar 0,441.

\section{SIMPULAN DAN SARAN}

Berdasarkan hasil analisis dan pembahasan, dapat ditarik kesimpulan sebagai berikut : 
1) Kepemimpinan $\left(X_{1}\right)$, Pemberdayaan $\left(X_{2}\right)$, Motivasi $\left(X_{3}\right)$ secara simultan atau bersama-sama berpengaruh signifikan terhadap kinerja pegawai Direktorat Penelitian dan Pengembangan Kementerian Pekerjaan Umum Timor Leste.

2) Kepemimpinan $\left(X_{1}\right)$, Pemberdayaan $\left(X_{2}\right)$, Motivasi $\left(X_{3}\right)$, secara secara parsial atau sendiri-sendiri berpengaruh signifikan terhadap kinerja pegawai Direktorat Penelitian dan Pengembangan Kementerian Pekerjaan Umum Timor Leste.

\section{SARAN}

Setelah mempelajari, menganalisis, membahas dan menarik kesimpulan maka penulis memberikan beberapa saran yang dapat dipergunakan sebagai bahan pertimbangan dalam menentukan kebijakan di masa mendatang.

Pemimpin perlu memperhatikan beberapa hal agar kinerja pegawai bisa ditingkatkan seperti perlunya menjelaskan prosedur kerja. Dengan pengarahan yang baik dan terarah dari pemimpin akan berdampak pada peninggkatan kinerja pegawai.

Pelatihan dan program capacity building perlu mendapatkan perhatian suapay kinerja pegawai bisa lebih ditingkatkan lagi. Dengan pelatihan dan program capacity building diharapkan ke depan karyawan lebih produktif dan berkualitas. Hal lain yang perlu diperhatikan adalah memberikan akses agar karyawan bisa memperoleh informasi berhubungan dengan pekerjaan mereka.

\section{REFERENSI}

Albert Kurniawan. 2009. Belajar mudah SPSS untuk Pemula.Yogyakarta : Mediakom. 
Arni Muhamad. 2008. Komunikasi Organisasi. Jakarta : PT Bumi Aksara.

Asli Nuryadin.2012. Manajemen Perusahaan. Yogyakarta : LaksBang PRESSindo.

Azman Ismail, Nur Baizura Natasha Abidin and Rabaah Tudin,2009. Prelationship Between Transformational Leadership, empowerment and Followers' Performance : An Empirical Study in Malaysia. Red de Revistas Científicas de América Latina, el Caribe, España y Portugal. Sistema de Información Científica. Vol 5 pp 5-22.

B. Maptuhah Rahmi. 2013. Pengaruh Kepemimpinan Transformasional terhadap Organizational Citizenship Behavior dan Komitmen Organisasional dengan Kepuasan Kerja Mediasi (Studi pada Guru Tetap SMA Negeri di Kabupaten Lombok Timur). Tesis, Program Magister Manajemen Universitas Udayana. Denpasar.

Brett Anthony Hayward.2005. Relationship Between Employee Performance, Leadership and Emotional Intelligence in South African Paratatal Organisation, Tesis, A thesis submitted in fulfilment of the requirement for the degree of Master of Commerce Departement of Mangement Rhodes University.

Brian E. Becker. 2010. Transforming Talent into strategic Impact. Jakarta : PPM.

Dewi Hanggraeni. 2012. Manajemen Sumber Daya Manusia. Jakarta : Lembaga Penerbit Fakultas Ekonomi Universitas Indonesia.

Dunn, M.W., Dastoor, B. and Sims, R.L. 2012. Transformational Leadership and Citizenship Behavior: Dengan Variabel Intervening Komitmen Multidisciplinary Research, Vol 4, No 1, pp. 45-59.Organisasional, Jurnal Ekonomi dan Kewirausahaan, Vol 8, No 1, pp. 25-37.

Dyne, L.V., Graham, J.W. \& Dienesch, R.M. 1994. Organizational citizenship behaviour: Con-struct redifinition, measurement, and valida-tion, Academy of Management Journal, 37 (4): 765-802.

Gomes, F.C., 2002,Manajemen Sumber Daya Manusia. Yogyakarta : Andi

Hadari Nawawi dan Martini Hadari. 2012. Kepemimpinan yang Efektif. Yogyakarta : Gadjah Mada University Press. 
Ghozali, Imam. 2004. Model Persamaan Struktural Konsep dan Aplikasi Dengan Program AMOS Versi 5.0. Semarang: Badan Penerbit Universitas Diponegoro.

Hadari Nawawi.2010. Perencanaan SDM. Cetakan Kelima. Yogyakarta : Gadjah Mada University Press.

Hakim. 2006. Analisis Pengaruh Motivasi, Komitmen Organisasi dan Iklim Organisasi terhadap Kinerja Pegawai pada Dinas Perhubungan dan Telekomunikasi Provinsi Jawa Tengah. JURNAL BISNIS Vol 2, No 2 : 165 180

Herrenkohl, R.C, Judson, G.T, and Heffner,J.A. E1999, Defining and Measuring Employee Empowerment. The Journal Of Applied Behavioral Science, 35(3): 373-389.

Khan, Sharafat, 1997. They Key to being a Leader Company: Empowerment, Journal Personality and Participation, pg 44-45

Hughes, R.L; Ginnet, R.C; and Curphy,GJ. 2012. Leadership (Memperkaya Pelajaran dari Pengalaman), Edisi ke Tujuh, Jakarta: Selemba Humanika.

Idayanti Nursyamsi. 2012. Pengaruh Kepemimpinan, Pemberdayaan, dan Stress Kerja Terhadap Komitmen Organisasional serta dampaknya terhadap Kinerja Dosen, Tesis, Program Magister ManajemenUniversitas Sultan Agung, Semarang.

Irham Fahmi. 2013. Perilaku Organisasi. Bandung : Alfabeta.

John C. Maxell.2010. Leadership Gold. Jakarta : Emanuel.

Kartono, 2006. Pemimpin dan Kepemimpinan, Jakarta : PT Rajagrafindo Persada.

Kaswan. 2013. Pelatihan dan Pengembangan. Bandung : Alfabeta.

Khan, Sharafat. 1997. The Key to being a Leader Company : Empowerment, Journal Personality and Partisipation, pg 44-45

Khuram Zafar Awan, Ibn-Waleed Qureshi and Sadiya Arif, 2012. THE EFFECTIVE LEADERSHIP STYLE IN NGOs: Impact of Servant Leadership Style on Employees' Work Performance and Mediation Effect of Work Motivation, International Journal of Economics and Management Sciences, Vol 1 No. 11, 2012, pp.43-56. 
Luthans, F. 2006. Perilaku Organisasi, Edisi Sepuluh, Yogyakarta: Penerbit Andi.

Maryoto, Susilo, 2000, Manajemen Sumber Daya Manusia. Yogyakarta: BPFE UGM.

Masrukhin dan Waridin. 2006. Pengaruh Motivasi Kerja, Kepuasan Kerja, Budaya Organisasi dan Kepemimpinan terhadap Kinerja Pegawai. Jurnal EKOBIS Vol 7, No 2 : 197-209.

Matthew, J., Grawhich, \& Barber, L. K., (2009). Are you Focusing both Employees and Organizational Outcomes. Organizational Health Initiative at Saint Louis University (ohi.slu@edu), 1-5.

Matthews, Virginia. 2006. Searching For Job Satisfaction. Liverpool Hope University (Online), Inggris. Available from: URL:http://www.media.com/searchCRM/downloads/CallCentreFDch17.pdf.

Meyer, J.P., Stanley, D.J., Herscovitch, L., and Topolnytsky, L. 2002. Affective, Continuance, and Normative Commitment to the Organization: A Metaanalysis of Antecedents, Correlates, and Consequences, Journal of Vocational Behavior, Vol 61, pp. 20-52.

Moeheriono.2009. Pengukuran Kinerja Berbasis Kompetensi. Bogor : Ghalia Indonesia

Notoatmodjo. 2009. Pengembangan Sumber Daya Manusia. Jakarta : Rineka Cipta.

P. Siagian.2004. Teori Motivasi dan Aplikasinya. Jakarta : Rineka Cipta

Paul J. Meyer. 2008. Pilar Kepemimpinan (Bagaimana Menjembatani Kesenjangan Kepemimpinan). Jakarta : Nafiri Gabriel.

Quratul-Ain Manzzor, 2010. Impact of Employess Motivation on Organizational Effectiveness, European Journal of Business and Management, Vol 3, No.3.

Riduwan. 2012. Dasar-Dasar Statistika. Bandung : Alfabeta.

Robert L. Mathis. 2011. Human Resource Mangement. Jakarta :Salemba Empat

Saifudin Anwar. 2011. Reliabilitas dan Validitas. Yogyakarta : Pustaka Pelajar. 
Simamora, H. 2004. Manajemen Sumber Daya Manusia. Edisi Ketiga. Yogyakarta: Sekolah Tinggi Ilmu Ekonomi YKPN.

Sri Wahyun. 2008. Faktor - Faktor yang Berpengaruh Terhadap Kinerja Pegawai pada Dinas Pertanian dan Peternakan Kabupaten Kutai Timur. Tesis. Program Magister Ilmu Administrasi Negara Fisipol Universitas ulawarman

Sudiro. 2010. Perencanaan Sumber Daya Manusia. Malang : Universitas Brawijaya Press

Sugiyono.2012. Metode Penelitian Kuantitatif Kualitatif dan R\&D. Bandung : Alfabeta.

Soeprihanto, John. 2000. Manajemen Sumber daya Manusia. Universitas Terbuka. Karunika, Jakarta

Sunjoyo, dkk. 2013. Aplikasi SPSS untuk Smart Riset. Bandung : Alfabeta.

Swarnalatha.C1, Prasanna.T.S2, 2012. A study on employee empowerment to motivate the employees in health care industry in a private multi-speciality organization, ASIAN JOURNAL OF MANAGEMENT RESEARCH, Volume 3 Issue 1.

Terry. 2006. Asas-Asas Menejemen. Bandung : PT Alumni.

Toni Setiawan. 2012. Manajemen Sumber daya manusia. Penerbit Platinum.

Wasty Soemanto. 1999. Pendidikan Wiraswasta. Jakarta : Bumi Aksara.

Wibowo.2007. Manajemen Kinerja. Jakarta : PT RajaGrafindo Persada.

Wilhelmus Andiyanto. 2010. Pengaruh Motivasi Kerja dan Kepemimpinan terhadap Kinerja pegawai pada Badan Keluarga Berencana dan Pemberdayaan Perempuan kabupaten Mangarai - Flores Nusa Tenggara Timur, Tesis, Program Magister ManajemenUniversitas Diponegoro, Semarang. 